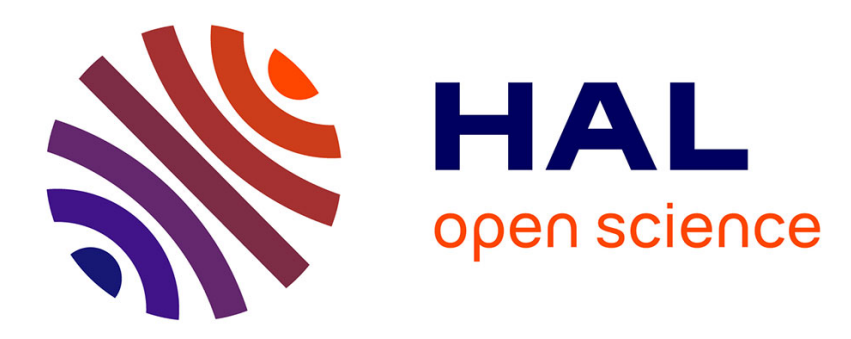

\title{
Visible Light Indoor Positioning in a Noise-aware Environment
}

\author{
Antonio Costanzo, Valeria Loscrì
}

\section{To cite this version:}

Antonio Costanzo, Valeria Loscrì. Visible Light Indoor Positioning in a Noise-aware Environment. WCNC 2019 - IEEE Wireless Communications and Networking Conference, Apr 2019, Marrakesh, Morocco. hal-02022610

\section{HAL Id: hal-02022610 https://hal.science/hal-02022610}

Submitted on 18 Feb 2019

HAL is a multi-disciplinary open access archive for the deposit and dissemination of scientific research documents, whether they are published or not. The documents may come from teaching and research institutions in France or abroad, or from public or private research centers.
L'archive ouverte pluridisciplinaire HAL, est destinée au dépôt et à la diffusion de documents scientifiques de niveau recherche, publiés ou non, émanant des établissements d'enseignement et de recherche français ou étrangers, des laboratoires publics ou privés. 


\section{Visible Light Indoor Positioning in a Noise-aware Environment}

\author{
$1^{\text {st }}$ Antonio Costanzo \\ Inria Lille - Nord Europe \\ antonio.costanzo@inria.fr
}

\author{
$2^{\text {nd }}$ Valeria Loscri \\ Inria Lille - Nord Europe \\ valeria.loscri@inria.fr
}

\begin{abstract}
Localization systems based on Visible Light Communication (VLC) are considered as good candidates for indoor environments, due to their high accuracy, low costs and the possibility of reusing existing infrastructures for both lighting and positioning. However, high level of environmental noises, mainly due to sunlight, significantly affect the performance of VLC positioning systems. A novel approach, for easily measuring environmental noises and compensating their effects, has been proposed in this work. Frequency Division Multiplexing (FDM) is adopted to divide the total bandwidth into a series of non-overlapping frequency sub-bands corresponding to each signal, while an estimation of Signal to Noise Ratio, obtained through real time Power Spectral Density measure, is exploited to compensate error positioning due to sunlight and other wideband external optical nice sources. Proposed approach has been validated through experimental tests, carried out using a simple deployment of low power lamps, extremely low cost hardware and a Software Defined approach. In the region under test, receiver positions have been experimentally detected according to an improved accuracy in comparison with classical FDM approach, confirming the correctness of proposed technique, according to low Signal to Noise Ratio levels.
\end{abstract}

\section{INTRODUCTION}

Visible Light Communication (VLC) [1] is an emerging technology, belonging to optical wireless communications, which allows the employment of Light Emitting Diodes (LED) for providing wireless data transmission. This paradigm, indeed, focuses on the exploitation of light sources normally used for illumination purposes. Visible light Paradigm could potentially offer extremely low cost communication and power consumption, a large unlicensed bandwidth and ubiquitous reuse of existing infrastructures, opening the possibility to several attractive applications, for example in those environments where Radio Frequencies are not allowed, like in particular units in hospitals, mines or petrochemicals plants. Another interesting aspect is the possibility of exploiting the signal received from LED sources for indoor positioning system. The characteristics of optical wireless signal, in addition to the ubiquity of LED lamps in almost all indoor environments, allow higher precision without a significant amount in terms of overall costs and complexity. Visible Light, in fact, could soon integrate or replace current indoor positioning techniques based on different technologies. Several different technologies, indeed, have been exploited for 1 allowing indoor positioning [2], based on ultrasound [3], infrared , radars [4], etc. However, a poor trade off between accuracy and flexibility of the these architectures, overall cost and size of the devices, have not permitted to achieve a wide diffusion of indoor positioning in the market. In order to exploit existing infrastructures and reduce costs, Wi-fi [5] Bluetooth [6] and RFID systems [7], [8]. are widely considered; however, the accuracy performed by Wi-Fi (some meters) is not suitable for most of possible indoor applications. Positioning systems based on Bluetooth show a high latency, while RFID need numerous infrastructure components installed and maintained in the working area. In this sense, VLC [1] represents one of the most attractive approaches for indoor positioning, due to the high achievable accuracy, low costs of the devices and the possibility of reusing existing infrastructures for both lighting and positioning. Several works have been carried out in recent years on this topic, following different approaches ( [9]). Performance comparison between Frequency Division Multiplexing (FDM) and Time Division Multiplexing (TDM) has been carried out in [10], through an extensive simulation campaign. In this case, best performance allowed an accuracy of $9.6 \mathrm{~cm}$, considering a perfect synchronization between transmitting LEDs. A significant effort in indoor positioning through visible light, in which frequency allocation is successfully exploited, has been provided in [11], achieving a $2.4 \mathrm{~cm}$ accuracy in ideal light conditions. However, few works deal with experimental results in a real environment and the most of them are based on fingerprinting. Moreover, data collection at the off-line training stage is quite time-consuming and sudden changes in natural light conditions during the day could completely prevent a correct position detection. In this paper, we propose an Indoor Positioning System based on Visible Light, based on low-cost components and a flexible architecture into respect with most of similar works, without the use neither of fingerprinting nor of auxiliary devices. Indeed, a novel approach based on real time monitoring and correction of environmental noise in the scenario has been exploited in order to compensate errors even in low Signal to Noise Ratio (SNR) conditions. The main contributions of the paper, in respect to the existing literature on Visible Light Positioning Systems, can be summarized as follows:

- Theoretical derivation of noise power impact on distance detection using a generic trilateration algorithm.

- Exploitation of the proposed theoretical analysis for reducing positioning error due to noisy optical signal in 
RSSI based Visible Light Indoor Positioning systems.

- Simple prototyping, based on Software Defined approach [12], [13], and experimental validation in a real operative scenario.

The paper is structured as follows. The Section II describes proposed architecture and its single components. In Section III we characterize the mathematical model to represent noise. In Section IV the experimental setup is described with the results evaluation. Finally, we conclude the paper in Section V.

\section{Software Defined VLC Positioning System}

A simplified scheme of our low cost illuminatingpositioning architecture, describing transmitting light devices is depicted in Fig. 1. A power line network feeds all the components of the system in the transmitting stage, namely the lamps and the LED drivers, composed of by a microcontroller and few other hardware components (resistances and transistors). In particular, warm white single LEDs are chosen for better providing illumination purposes and lamp blinking is controlled in order to generate signals at different frequencies. The receiver, in fact, distinguish beams from different transmitters, following a modified version of a RF Carrier Allocation Technique, but including dedicated channels for environmental noise monitoring. The main operations performed by the Software Defined Visible Light Indoor Positioning System are resumed in the block diagram in Fig. 2. In particular, receiving stage performs the following steps:

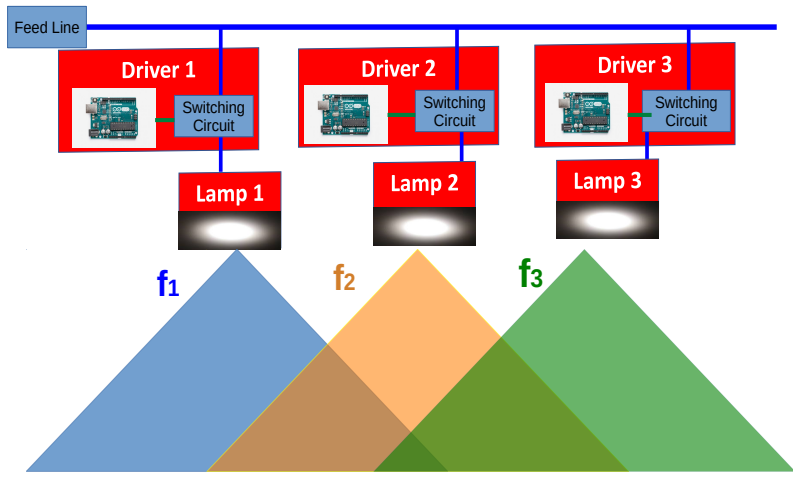

Fig. 1. Transmitting system.

- Optical signal is detected, pre-filtered and amplified.

- Analog to digital conversion, buffering and timing are performed by a low cost single board in [14], [15].

- Signal is sort out in three different paths, each one containing a high $\mathrm{Q}$ factor peak filter. In this way, it is possible to properly separate the contribution of power radiated by each lamp. A fourth additional path is implemented in order to roughly evaluate environmental noise outside the bandwidth.

- For each stage, Power Spectral Density is dynamically calculated and integrated in proper frequency ranges in order to determinate power contributions coming from illuminating sources and providing a noise estimation, using a Frequency Division Multiplexing (FDM) approach.

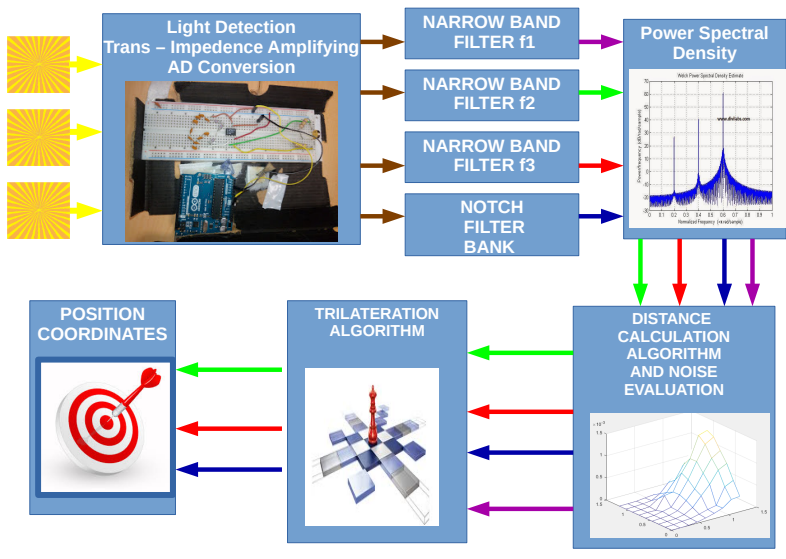

Fig. 2. Receiving system.

- Distances between the receiver and each transmitter is calculated considering Received Signal Strength Indicator (RSSI) measurement for each stage, according to optical channel characteristics.

- Measured noise values in the fourth stage are properly processed in order to mitigate the error.

- Corrected distance values are given in input to a trilateration algorithm for estimating the position of the receiver.

\section{INDOOR POSITIONING IN A NOISY ENVIRONMENT}

The first step performed by the proposed receiver is the evaluation of Power Spectral Density in the frequency band of each transmitting source. In particular, corresponding received power values $\left(P_{r i}, i=[1,3]\right)$ are calculated as following:

$$
P_{r i}=\int_{f i-\frac{f_{i}}{Q_{i}}}^{f i+\frac{f_{i}}{Q_{i}}} \operatorname{PSD}\left[x_{i}(t)\right] d f
$$

where $x_{r i}(t)$, is the time domain signal coming from the $i^{\text {th }}$ transmitter after acquisition, amplifying, conditioning and filtering. $Q_{i}$, is the quality factors of related peak filter and the operator DSP[.] indicates Power Spectral Density of the signal. The ratio between the optical radiated power in the main direction $P_{\text {Topt }}$, and the received optical power at a certain distance $d$ can be modeled considering the LED as a Lambertian source. Indeed, assuming that the $-3 \mathrm{~dB}$ beam width of the LED is equal to $\phi_{-3 d B}$, received power can be calculated as follows [16]:

$$
P_{\text {Ropt }}=P_{\text {Topt }} \frac{(m+1) A}{2 \pi d^{2}} \cos ^{m}(\phi) T(\psi) g(\psi)
$$

being:

- $A$ the effective area of the photodiode;

- $d$ the distance between transmitter and receiver;

- $\phi$ the angle of irradiance with respect to the axis normal to the transmitter surface;

- $\psi$ the angle of incidence with respect to the axis normal to the receiver surface;

- $T(\psi)$ the gain of optical filter; 
- $G(\psi)$ the receiver optical concentrator gain;

- $m$ the order of the Lambertian Radiation

In particular, Lambertian order is calculated as follows

$$
m=\frac{\ln 2}{\ln \left(\cos \left(\phi_{-3 d B}\right)\right)}
$$

while the gain of the optical concentrator can be calculated, starting by its refraction index $\eta$ and by the field of view of the receiver $\psi_{0}$, as follows:

$$
G(\psi)=\frac{\eta^{2}}{\sin ^{2}\left(\psi_{0}\right)}
$$

The relation between electrical measured power and optical received power, depends on the responsivity $R_{p}$ and the area $\mathrm{A}$ of the photo-diode. A further calibrating factor $\xi$ is introduced for taking into account trans-impedance gain of the remaining hardware front-end and other effects at the receiving side. In particular, the relation $\zeta$ between optical power $P_{o p t}$ and electrical power $P_{e l}$ can be calculated as follow:

$$
\zeta=\frac{P_{e l}}{P_{o p t}}=\frac{R_{p} \xi}{A}
$$

The distances $d_{i}$, between each transmitter and the receiver is so estimated by measured power at the receiver and optical transmitted power $P_{\text {Topt }}$ after each processing phase as described in 6.

$$
d_{i}=\sqrt{\frac{(m+1) A \zeta \cos ^{m} P_{\text {Topt }}(\phi) T(\psi) g(\psi)}{2 \pi \int_{f i-\frac{f_{i}}{Q_{i}}}^{f i+\frac{f_{i}}{Q}} P S D\left[x_{i}(t)\right] d f}}
$$

Received signals are filtered and integrated in a narrow band, in order to strongly reduce interference due to other artificial light sources in the scenario. However, a significant amount of noise affecting the detection is due to sunlight and other wide-band source noises. In this work, the problem of non line of sight transmission is not yet faced, however some interesting approach could be exploited in a future extension of this work, following a similar approach of the one proposed in [17]. However, we propose a novel method to take into account real time noise variations, based on measurement in a dedicated channel, like shown in Fig. 2. Since thermal noise and sunlight incident power affect the system at all frequencies, spectral noise components outside the transmitting ranges are integrated in order to provide an estimation of total noise in the system. In fact, since transmitters work in a very narrow range, we just considered outside average noise level outside the bandwidth, as the same noise level acting inside transmitting ranges (where a clear distinction between noise and useful signal is not trivial to be measured in real time). In particular, being $x_{N}(t)$ the noise component measured after filtering transmitting source signal (the fourth stage in Fig. 2), and $B$ the total bandwidth of the system, the overall estimation of overall environmental power, $N_{\text {out }}$, is calculated as follows:

$$
\begin{aligned}
N_{\text {out }}= & \int_{0}^{f 1-\frac{f_{1}}{Q_{1}}} \operatorname{PSD}\left[x_{N}(t)\right] d f+\int_{f 1+\frac{f_{1}}{Q_{1}}}^{f 2-\frac{f_{2}}{Q_{2}}} \operatorname{PSD}\left[x_{N}(t)\right] d f+ \\
& +\int_{f 2+\frac{f_{2}}{Q_{2}}}^{f 3-\frac{f_{3}}{Q_{3}}} P S D\left[x_{N}(t)\right] d f+\int_{f 3+\frac{f_{3}}{Q_{3}}}^{B} P S D\left[x_{N}(t)\right] d f
\end{aligned}
$$

Considering a constant amount of average noise in bandwidth, an indirect estimation of noise power in each corresponding transmitting range has been defined, starting by $N_{\text {out }}$, just calculating the proportion of noise in each bandwidth, namely:

$$
N_{r i}=\frac{2 f_{i}}{Q_{i} B} N_{\text {out }}\left(1+\frac{\sum_{k=1}^{n} \frac{2 f_{k}}{Q_{k}}}{B}\right)
$$

being $i$ the index of each transmitter, $n$ the number of transmitters (in our case $(n=3)), \frac{2 f_{i}}{Q_{i}}$ its corresponding frequency range of the received signal, while the term $N_{\text {out }}\left(1+\frac{\sum_{k=1}^{n} \frac{2 f_{k}}{Q_{k}}}{B}\right)$, represents the estimated noise in the overall receiving bandwidth. Once the estimated noise for each path has been calculated, signal to noise ratio for each frequency range can be simply calculated as the ratio between useful power $P_{r i}^{*}$ over measured noise, namely:

$$
S N R_{i}=\frac{P_{r}^{*}}{N_{r i}}=\frac{P_{r i}-N_{r i}}{N_{r i}}
$$

A simple reference system has been considered and shown in Fig. 3. The receiver is located in the plane xy, at a distance $d_{1}$, $d_{2}$ and $d_{3}$ by the transmitters. The relation between the ideal

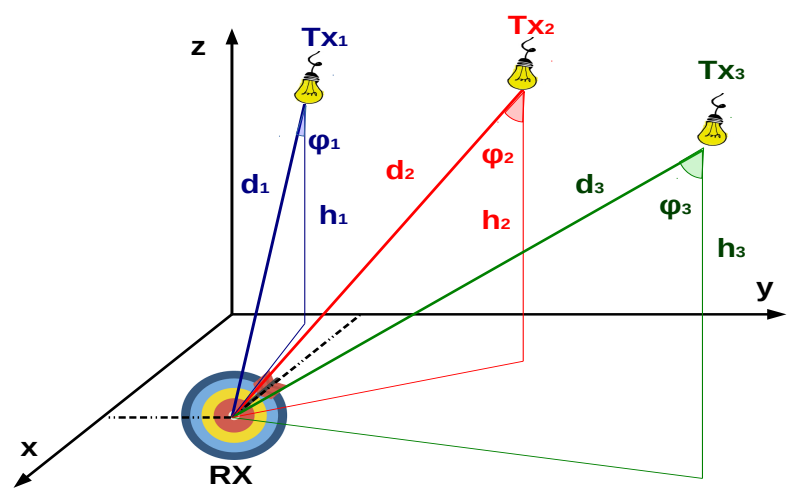

Fig. 3. Reference system

distance $d_{i}^{*}$ and the $i^{\text {th }}$ transmitter in absence of noise, can be related to the real distance, affected by noise, as following described. From (2) and (5) one can obtain, :

$$
\cos ^{m}\left(\phi_{i}\right)=\frac{2 \pi d_{i}^{* 2} P_{r i}^{*}}{(m+1) A \zeta P_{\text {Topt }}(\phi) T(\psi) g(\psi)}
$$

and, finally:

$$
d_{i}^{*}=\left(\frac{h_{i}^{m}(m+1) A \zeta P_{\text {Topt }}(\phi) T(\psi) g(\psi)}{2 \pi P_{r i}^{*}}\right)^{\frac{1}{m+2}}
$$


According to (11), the real distance $d_{i}$ in presence of noise, can be alternatively expressed as:

$$
d_{i}=\left(\frac{h_{i}^{m}(m+1) A \zeta P_{T o p t}(\phi) T(\psi) g(\psi)}{2 \pi P_{r i}}\right)^{\frac{1}{m+2}}
$$

According to (11) and (12), the relative error $\Delta d_{i}$ between real and ideal distances, can be expressed as in (13).

$$
\Delta d_{i}=1-\frac{d_{i}}{d_{i}^{*}}=1-\left(\frac{P_{r i}}{P_{r i}^{*}}\right)^{-\frac{1}{m+2}}
$$

Replacing (9) into (11), the final expression for the relative error, is described in (14).

$$
\Delta d_{i}=1-\left(1+\frac{1}{S N R}\right)^{-\frac{1}{m+2}}
$$

Once the input error is determined, it is taken into account in the positioning algorithm in order to evaluate, and eventually correct, final errors in positioning. For this aim, we use the classical formulation of the trilateration problem, considering the unknown coordinates of the receiver as the intersection of three circles centered in the known coordinates of the transmitters. In particular, being $\mathrm{x}, \mathrm{y}$ and $\mathrm{z}$ the unknown coordinates of the receiver, $x_{i}, y_{i}$ and $z_{i}$ the known coordinates of the $i^{t h}$ transmitter, one can write: $A \boldsymbol{x}=\mathbf{b}$, where:

$$
A=\left[\begin{array}{cccc}
1 & -2 x_{1} & -2 y_{1} & z_{1} \\
1 & -2 x_{2} & -2 y_{2} & z_{2} \\
1 & -2 x_{3} & -2 y_{3} & z_{3}
\end{array}\right], x=\left[\begin{array}{c}
x^{2}+y^{2}+z^{2} \\
x \\
y \\
z
\end{array}\right]
$$

and

$$
b=\left[\begin{array}{l}
d_{1}^{2}-x_{1}^{2}-x_{2}^{2}-x_{3}^{2} \\
d_{2}^{2}-y_{1}^{2}-y_{2}^{2}-y_{3}^{2} \\
d_{3}^{2}-z_{1}^{2}-z_{2}^{2}-z_{3}^{2}
\end{array}\right]
$$

In this work we refer to the algebraic solution for trilateration and multilateration proposed in [18]. In addition, we introduced in the algorithm the input error defined in (14), computing the error affecting measured position. Being $\boldsymbol{x}^{*}=\left[x^{*}, y^{*}, z^{*}\right]$ the vector of receiver position without taking effect of environmental noise, calculated using the vector $\boldsymbol{d}=\left[d 1^{*}, d 2^{*}, d 3^{*}\right]$ as theoretically defined in (6), one can write

$$
A \boldsymbol{x}^{*}=\boldsymbol{b}^{*}=\left[\begin{array}{l}
d_{1}^{* 2}-x_{1}^{2}-x_{2}^{2}-x_{3}^{2} \\
d_{2}^{* 2}-y_{1}^{2}-y_{2}^{2}-y_{3}^{2} \\
d_{3}^{* 2}-z_{1}^{2}-z_{2}^{2}-z_{3}^{2}
\end{array}\right]
$$

while, the vector or receiver position $\boldsymbol{x}^{r}=\left[x^{r}, y^{r}, z^{r}\right]$, taking into account the effects of noise in the environment. Corrected coordinates can be written considering the definition in (14), and changing the distance vector as follows.

$$
A \boldsymbol{x}^{\boldsymbol{r}}=\boldsymbol{b}^{\boldsymbol{r}}=\left[\begin{array}{c}
\left(1+\Delta d_{1}\right) d_{1}^{*^{2}}-x_{1}^{2}-x_{2}^{2}-x_{3}^{2} \\
\left(1+\Delta d_{2}\right) d_{2}^{* 2}-y_{1}^{2}-y_{2}^{2}-y_{3}^{2} \\
\left(1+\Delta d_{3}\right) d_{3}^{*^{2}}-z_{2}^{2}-z_{3}^{2}
\end{array}\right]
$$

The vector $\boldsymbol{x}_{\text {err }}=\left[x_{\text {err }}, y_{\text {err }}, z_{\text {err }}\right]$, representing the error (considering each coordinate) due to noise in the environment, can be simply estimated as the difference between these trilateration results, namely:

$$
x_{e r r}=x^{r}-x^{*}
$$

This formulation can be useful for compensating the effect of environmental noise given to a particular topology of transmitters and a given level of noise, without adding any significant amount of complexity.

\section{EXPERIMENTAL VALIDATION}

An experimental setup, for validating the proposed visible light positioning approach, is provided in this section. We provide a comparison between:

- measurements according to classical FDM approach, without compensation of the noise power;

- measurements according to the proposed noise awareness approach, where environmental noise level is measured in each point of the xy plane, simultaneously with the power associated to the transmitting blinking ranges, in order to compensate positioning errors, according to the description provided in previous sections.

Three identical transmitters have been used, each one composed by the following hardware components.

- A commercial warm white LED (XLamp MC-E warm, produced by CREE);

- An Arduino Uno board, generating the transmitting signal for driving the led.

- A driving circuit, composed by resistors and transistors.

- A power supply, feeding the led (operating voltage 12V) and the Arduino (operating voltage 5V).

The receiver is composed by the following hardware components:

- A commercial photodiode (OSD15-5T, fabricated by Centronic).

- A trans-impedance amplifying and pre-filtering circuit composed by a low cost operational amplifier (LTC1050), low cost resistors and capacitors.

- An Arduino board, for data acquisition and analog digital conversion.

Low frequency square waves, but guaranteeing no flickering problems $(125 \mathrm{~Hz}, 166.7 \mathrm{~Hz}$ and $200 \mathrm{~Hz})$ have been chosen for LED blinking. This choice has been done to avoid high performance micro-controllers in the transmitting stage and allow the possibility of using the proposed approach not only with LED, but even with those illuminating lights, like fluorescent ones, which allow very low switching between on and off period. The receiver has been placed on each point of a grid made up by 9x9 points, with an extension of $120 \times 120 \mathrm{~cm}$. Both compensated and uncompensated positions have been determined for each point of the grid in the $x y$ plane and compared with the real position of the receiver, for evaluating the accuracy of the system. In order to provide a validation of the proposed Light Indoor Positioning technique in a critical noisy environment, the setup shown in Fig. 4 has been considered. In particular, a typical use case, where 


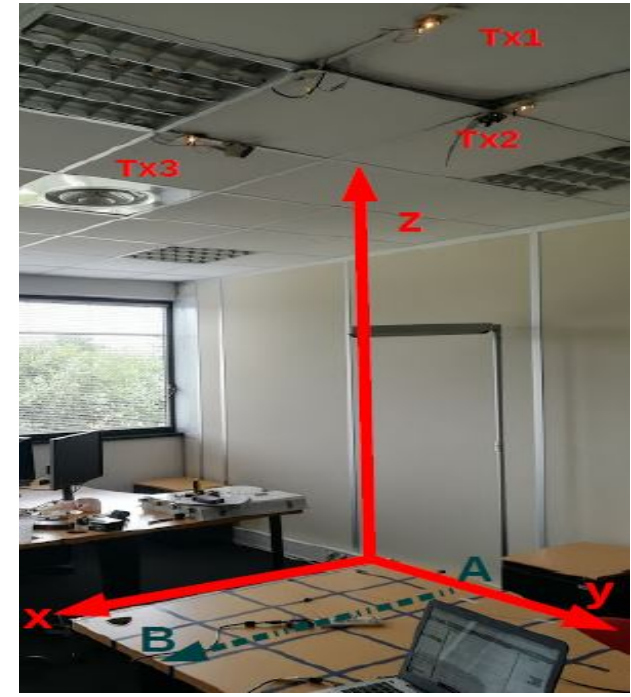

Fig. 4. Experimental Tests in a real use case setup: Overall System

the position of an item (the receiver) on a table has to be detected using illuminating lamps on the ceiling, has been realized. Distance between the table and the ceiling is equal to $2 \mathrm{~m}$. Considering this setup, a daily measurement campaign (from 8:00 to 20:00) has been carried out in a sunny day, with windows facing north in the North Hemisphere, sunrise at 5:53 and sunset at 21:36.

In particular, three measurement sessions of two hours have been carried out, where receiver position has been recorded each 15 minutes and a mean has been calculated for each session. In order to evaluate the effect of sunlight variation, Signal to Noise Ratio (SNR) at the beginning of each session is measured through the additive channel of proposed architecture and provided in Fig. 5, 6, and 7, considering one of the three transmitters.

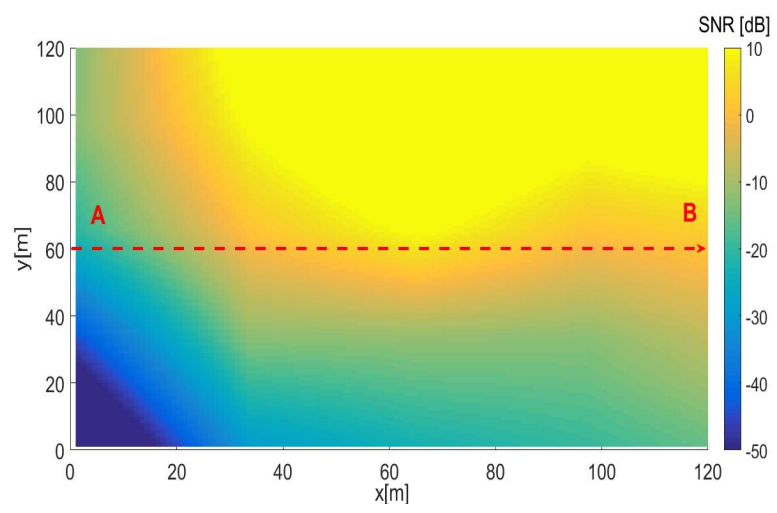

Fig. 5. Averaged Measured Signal to Noise Ratio for TX1, time: 8:00-10:00

It can be noticed how a very poor SNR is measured, especially in the areas near to the windows and farther from the transmitter, namely for low values of y coordinate, according to reference system in Fig. 4. A significant difference, during the day, can been shown, due to the intensity of sunlight

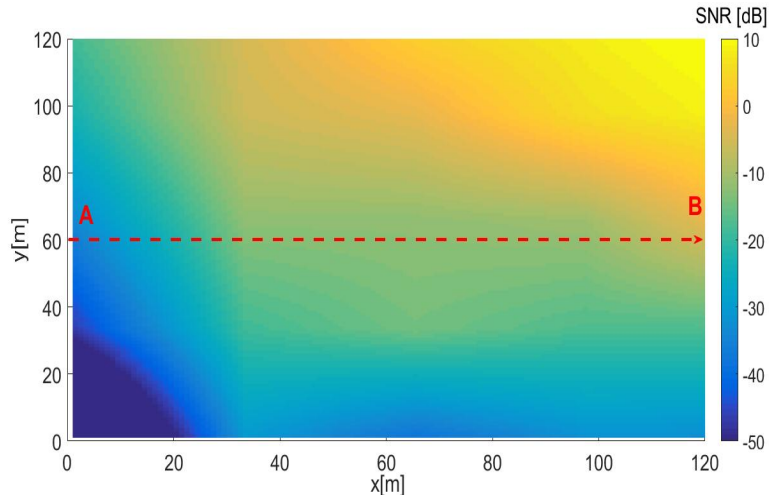

Fig. 6. Averaged Measured Signal to Noise Ratio for TX1, time: 13:00-15:00

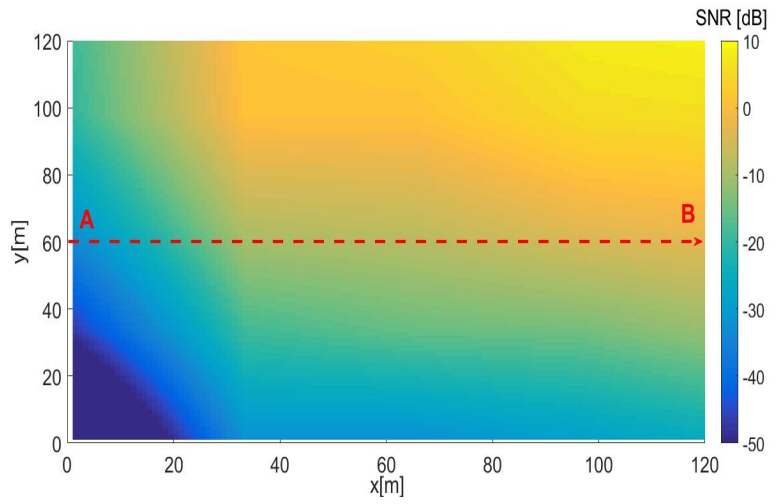

Fig. 7. Averaged Measured Signal to Noise Ratio for TX1, time: 18:00-20:00

and reciprocal position between the sun and the window of the office room. Averaged values between measures taken each 15 minutes, have been considered for each session and shown in Fig. 8,9 and 10, considering the path between point $\mathrm{A}=[0,60,0] \mathrm{cm}$ and point $\mathrm{B}=[120,60,0] \mathrm{cm}$.

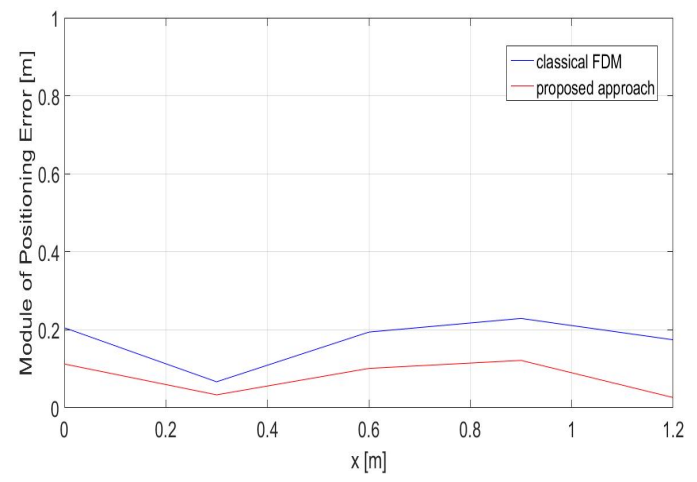

Fig. 8. Average error of proposed VLC indoor positioning system, time: 8:00-10:00

Even in extremely hard noisy conditions, proposed noise aware approach significantly mitigates error positioning in respect to the classical FDM-RSSI approach, allowing the possibility of using indoor positioning based on VLC also in real use case where a high SNR is not achievable due to 


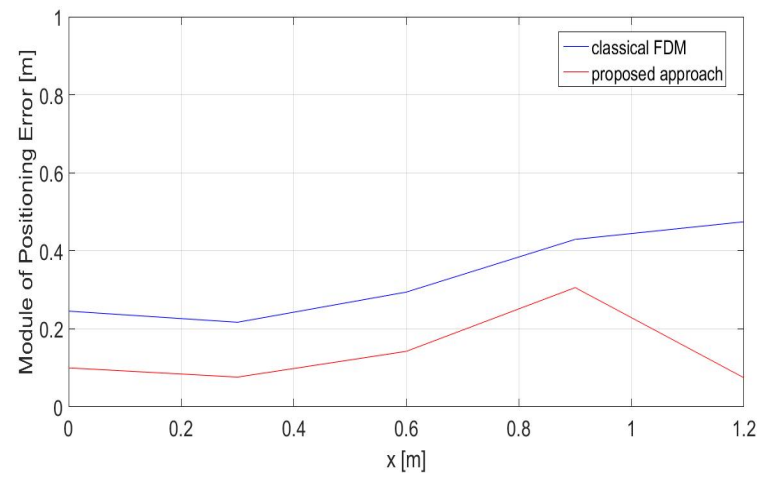

Fig. 9. Average error of proposed VLC indoor positioning system

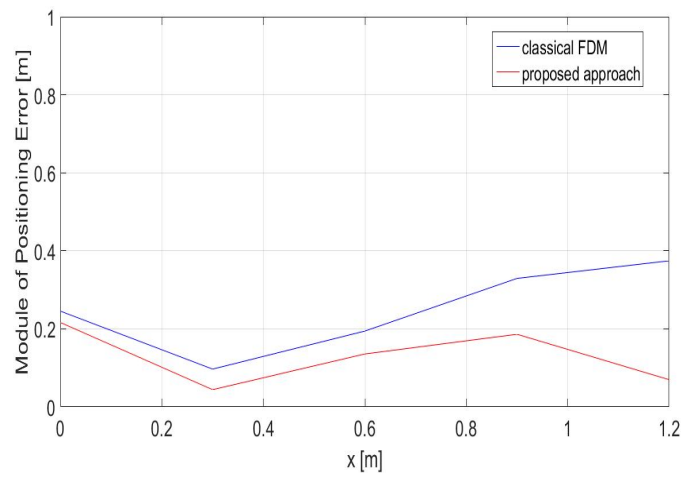

Fig. 10. Average error of proposed VLC indoor positioning system, time: 18:00-20:00

disturbing sunlight, and other error sources. If we compare our results with last experimental validations recently appeared in literature according to the survey in [9], our system overcomes other FDM systems and achieves, in general, a competitive level of accuracy, nevertheless the extremely low cost hardware employed.

\section{CONCLUSIONS AND FUTURE WORKS}

A low cost indoor positioning system, based on a real time monitoring of environmental noise, has been proposed in this work. Low cost equipment has been used in our architecture and a competitive accuracy, in comparison with a classical FDM-RSSI without noise awareness integrated, has been performed. The proper manipulation of measured received power spectral density inside frequency ranges allocated for LED transmissions, and outside these ranges for environmental noise, represents a novel way to face the problem of disturbing signals in the scenario, mainly due to sunlight, which represents the main problem to a wide diffusion of indoor positioning system based on visible light. Numerical simulations have been carried out and experimental results on a $2 \mathrm{D}$ grid of $1.20 \mathrm{~m} \times 1.20 \mathrm{~m}$ illuminated low power LEDs, have been performed, achieving an high accuracy in the main area of the scenario under analysis and a significant compensation in peripheral areas, where Signal to Noise values are lower. No hybrid architecture or auxiliary devices have been considered nor in the model, neither in the experimental setup. A further extension of this work will deal with the integration of the effects of multi-path in the channel model.

\section{REFERENCES}

[1] S. Dimitrov and H. Haas, Principles of LED Light Communications: Towards Networked Li-Fi. Cambridge University Press, 2015.

[2] Y. Gu, A. Lo, and I. Niemegeers, "A survey of indoor positioning systems for wireless personal networks," IEEE Communications Surveys Tutorials, vol. 11, no. 1, pp. 13-32, First 2009.

[3] A. Harter and A. Hopper, "A distributed location system for the active office," IEEE Network, vol. 8, no. 1, pp. 62-70, Jan 1994.

[4] P. Bahl and V. N. Padmanabhan, "Radar: an in-building rf-based user location and tracking system," in Proceedings IEEE INFOCOM 2000. Conference on Computer Communications. Nineteenth Annual Joint Conference of the IEEE Computer and Communications Societies (Cat. No.00CH37064), vol. 2, 2000, pp. 775-784 vol.2.

[5] P. Prasithsangaree, P. Krishnamurthy, and P. Chrysanthis, "On indoor position location with wireless lans," in The 13th IEEE International Symposium on Personal, Indoor and Mobile Radio Communications, vol. 2, Sept 2002, pp. 720-724 vol.2.

[6] J. Hallberg, M. Nilsson, and K. Synnes, "Positioning with bluetooth," in 10th International Conference on Telecommunications, 2003. ICT 2003., vol. 2, Feb 2003, pp. 954-958 vol.2.

[7] C. Wang, Z. Shi, F. Wu, and J. Zhang, "An rfid indoor positioning system by using particle swarm optimization-based artificial neural network," in 2016 International Conference on Audio, Language and Image Processing (ICALIP), July 2016, pp. 738-742.

[8] S. Costanzo, A. Costanzo, A. Raffo, and A. Borgia, "Environmental effects on the performances of a uhf passive tag-based commercial rfid system," in New Advances in Information Systems and Technologies.

[9] Y. Zhuang, L. Hua, L. Qi, J. Yang, P. Cao, Y. Cao, Y. Wu, J. Thompson, and H. Haas, "A survey of positioning systems using visible led lights," IEEE Communications Surveys Tutorials, vol. PP, no. 99, pp. 1-1, 2018.

[10] U. Nadeem, N. Hassan, M. Pasha, and C. Yuen, "Indoor positioning system designs using visible led lights: performance comparison of tdm and fdm protocols," Electronics Letters, vol. 51, no. 1, pp. 72-74, 2015.

[11] H. S. Kim, D. R. Kim, S. H. Yang, Y. H. Son, and S. K. Han, "An indoor visible light communication positioning system using a rf carrier allocation technique," Journal of Lightwave Technology, vol. 31, no. 1, pp. 134-144, Jan 2013.

[12] S. Costanzo, G. D. Massa, A. Costanzo, L. Morrone, A. Raffo, F. Spadafora, A. Borgia, G. Formetta, G. Capparelli, and P. Versace, "Low-cost radars integrated into a landslide early warning system," in Advances in Intelligent Systems and Computing.

[13] S. Costanzo, G. D. Massa, A. Costanzo, A. Borgia, A. Raffo, G. Viggiani, and P. Versace, "Software-defined radar system for landslides monitoring," in Advances in Intelligent Systems and Computing.

[14] A. Costanzo and V. Loscri, "Demo: A Context Aware Algorithm for an Adaptive Visible Light Communication System," in EWSN 2018 - International Conference on Embedded Wireless Systems and Networks, Madrid, Spain, Feb. 2018. [Online]. Available: https://hal.inria.fr/hal-01686565

[15] A. Costanzo, V. Loscri, and S. Costanzo, "Adaptive Dual Color Visible Light Communication (VLC) System," in 6th World Conference on Information Systems and Technologies, Napoli, Italy, Mar. 2018. [Online]. Available: https://hal.inria.fr/hal-01687543

[16] G. Cossu, M. Presi, R. Corsini, P. Choudhury, A. M. Khalid, and E. Ciaramella, "A visible light localization aided optical wireless system," in 2011 IEEE GLOBECOM Workshops (GC Wkshps), Dec 2011, pp. 802 807.

[17] C. Huang and X. Zhang, "Los-nlos identification algorithm for indoor visible light positioning system," in 2017 20th International Symposium on Wireless Personal Multimedia Communications (WPMC), Dec 2017, pp. 575-578.

[18] A. Norrdine, "An algebraic solution to the multilateration problem," in International Conference on Indoor Positioning and Indoor Navigation, 112012. 